\title{
Correlation of Plasma Kynurenic Acid Level with the Severity of Depression, Pain, And the Need of Opioids for Pain Management in Cancer Patients in Palliative Care Unit in Dr. Soetomo General Hospital Surabaya
}

\author{
Rizky Iman Kurniawan'1, Arie Utariani ${ }^{2 *}$, Dedi Susila² \\ 1Resident, Departement of Anesthesiology and Reanimation, Faculty of Medicine \\ Airlangga University, Dr. Soetomo General Hospital, Surabaya \\ ${ }^{2}$ Consultant, Departement of Anesthesiology and Reanimation, Faculty of Medicine \\ Airlangga University, Dr. Soetomo General Hospital, Surabaya \\ *Corresponding author details: Arie Utariani; utarianiarie@gmail.com
}

\begin{abstract}
Introduction: Most cancer cases in Indonesia are diagnosed at an advanced stage, and the cure rate and life expectancy are not as expected. Depression and pain are the most common problems that arise in cancer patients. Kynurenic acid and quinolinic acid are neuroactive metabolites produced in the kynurenine pathway. Decreased kynurenic acid levels have been reported to be associated with depression, pain, and pathology in cancer.

Objective: This study aims to determine the correlation between kynurenic acid levels and the severity of depression, pain level, and opioid need in cancer patients undergoing palliative treatment.

Material and Method: This study was an observational analytic study with a retrospective cohort design. The study population was adult patients with malignancy in the palliative care unit of Dr. Soetomo General Hospital Surabaya that received opioid treatment during the study period. The sample of this study was 54 patients. Plasma kynurenic acid levels were measured using the 'Human Kynurenic acid ELISA kit' from BT Lab. The severity of depression was measured by the Hamilton Depression Rating Scale (HDRS). Pain level was scored with Pain Numeric Rating Scale (NRS), while the opioid use was collected from the patient's medical record.

Result and Discussion: There was a significant relationship between kynurenic acid levels and the severity of depression $(\mathrm{p}<0.001)$, pain level $(\mathrm{p}<0,001)$, and opioid need $(\mathrm{p}=0,007)$. Simple linear regression analysis showed that the lower the kynurenic acid level, the more severe the depression $(\mathrm{p}<0.001)$ and the higher the opioid dose needed $(\mathrm{p}=0,004)$. Moderate pain has a lower median kynurenic acid level than mild pain, $12.32 \mathrm{nmol} / \mathrm{L}$, and $16.29 \mathrm{nmol} / \mathrm{L}$, respectively. Patients with a lower level of kynurenic acid require a higher dose of the same type of opioid.

Conclusion: The lower level of plasma kynurenic acid is associated with more severe depression, more pain level, and more opioid need for pain management in malignancy patients in the palliative care unit of Dr. Soetomo General Hospital Surabaya.
\end{abstract}

Keywords: kynurenic acid; depression; pain; opioid; malignancy; palliative care

\section{INTRODUCTION}

Malignancy is one of the non-communicable diseases that contribute to the leading cause of death worldwide.(1) GLOBOCAN data from the International Agency for Research on Cancer (IARC) in 2020 stated roughly 11 million new cases of malignancy and nearly 10 million deaths due to malignancy worldwide.International Agency for Research on Cancer (IARC) Based on Basic Health Research (Riset Kesehatan Dasar, Riskesdas) report in 2018 , the prevalence of malignancy patients in Indonesia increased from 1.4 per 1,000 population in 2013 to 1.79 per 1,000 population in 2018. Meanwhile, in East Java province, in 2018, the prevalence of malignancy was 1.6 per 1000 population.(3).
Most cases of malignancy in Indonesia are diagnosed at an advanced stage, and the cure rate and life expectancy are not as expected. When curative treatment has not been able to provide the expected cure and preventive efforts, both primary and secondary, have not been carried out properly so that most patients are found in an advanced stage, palliative care should be the only pragmatic service and a humane answer (4).

Malignant patients experience suffering that requires an integrated multi-disciplinary approach to have a good quality of life and ultimately die with dignity. The integration of palliative care in the integrated management of malignancy has been recommended by the World Health Organization (WHO) in line with the increasing number of malignancy patients and the death rate due to malignancy. 
Patients with malignancy in palliative care include chronic pain and depressive disorders.(5)

Analgesics and adjuvant therapy are essential to control pain in the palliative care of patients with malignancy. The administration of non-steroidal anti-inflammatory drugs (NSAIDs) alone is often inadequate, and the administration of opioids must be done with caution because it can cause side effects such as impaired consciousness, delirium, hallucinations, myoclonus, and respiratory depression. $(6,7)$

Depressive disorder is one psychosocial problem that arises in patients with malignancy.(8)(8) The result of the study shows that $34.4 \%$ of cancer patients in Indonesia have depression. This figure increases in line with the increasing severity of morbidity and disease stage.(9) Depressive disorders can increase the patient's perception of pain, decrease sensitivity to treatment efficacy, prolong hospital stay, and lead to suicidal ideation or actions.(10)

Kynurenic acid (KYNA) and quinolinic acid (QUIN) are neuroactive metabolites that are the product of the kynurenine pathway - the main catabolic pathway of tryptophan.(11) Kynurenic acid and quinolinic acid can influence the development of pain hypersensitivity and depressive disorders through their direct action on NMDA receptors and their relationship with serotonin synthesis.(12) Kynurenic acid is an NMDA receptor antagonist, while quinolinic acid is an NMDA receptor agonist. A decrease in the kynurenic acid ratio to quinolinic acid has been reported to be associated with major depressive disorder.(13)Meta-analytical studies have shown a significant reduction in quinolinic acid (KYNA) levels in patients with depressive disorders.(14)Another study also mentioned that KYNA could also be a potential biomarker in diagnosing depression patients.(15) In addition to decreased levels of KYNA in depressive disorders, a recent study demonstrated that administration of KYNA induced antidepressant-like effects in an animal model of depression.(16) Thus, the kynurenine pathway can be a biomarker and therapeutic target for chronic pain and depressive disorders.(11)

There is an increase in kynurenic acid levels in patients with malignancy, with concentrations ranging from 21.3 to $250 \mathrm{nM}$ depending on the type of malignancy.(17) Chronic systemic inflammatory conditions in malignancy will trigger the activation of the kynurenine pathway, thereby increasing the levels of its metabolites, specifically kynurenic acid and quinolinic acid, as well as decreasing serotonin synthesis. An increase in quinolinic acid and a decrease in serotonin levels will exacerbate pain and depressive disorders.(12)

Only a few studies investigate the relationship between kynurenic acid levels with depressive disorder and the need for opioids for pain management in malignancy patients. Several previous studies have evaluated kynurenic acid as a mechanical biomarker in chronic pain and depressive disorders, but no studies have specifically evaluated malignancy in patients undergoing palliative care.
Increased levels of neuroprotective kynurenic acid may be associated with a decrease in the degree of depressive disorder and the need for opioids for pain control. Thus, we assume it necessary to conduct a study to analyze the relationship between kynurenic acid levels with depressive disorder, the degree of pain, and the need for opioids for pain management in malignancy patients under palliative care.

\section{METHOD}

This study was correlative analytic observational study with cross-sectional design with retrospective secondary data. Held in the Palliative Care Unit Dr. Soetomo General Hospital during May till September 2021. The population came from all adult patients with malignancy in Palliative Care Unit Dr. Soetomo General Hospital who had opioid therapy during study period. Samples were obtained using consecutive sampling method with minimum sample size was 41 patients. The inclusion criteria are the patients aged minimum 18 years old, diagnosed with malignancy, had opioid therapy, and agreed to be study subject.

During the palliative care unit visit, patients who met the inclusion criteria then had interviewed by trained doctor in Palliative Care Unit based on Hamilton Depression Rating Scale (HDRS) to assess depression severity and Numerical Rating Scale (NRS) to assess pain severity. Blood samples $(3 \mathrm{cc}$ ) were collected to measure kynurenic acid level using Human Kynurenic acid ELISA kit (BT Lab). Patients' data including the need of opioid, age, sex, diagnosis and stadium of malignancy were obtained from medical record which documented in patients' last visit to palliative care unit.

Severity of depression assessed from HDRS-17 questionnaire scoring was further grouped into: no depression ( $\leq 7)$, mild (8-13), moderate (14-18), and severe (19-22). Severity of pain assessed using Numerical Rating Scale (NRS) were classified into: no pain (0), mild (1-4), moderate (5-6), and severe (7-10). Opioid dose requirement was further converted into milligram morphine equivalent (MME) using formula:

Strength per unit $\mathrm{x}$ (number of units / days supply) x MME conversion factor $=$ Daily MED

The normality of the data was tested using KolmogorovSmirnov sample test. To compare the level of kynurenic acid in more than two groups (variable: depression severity, pain severity, the need of opioid), a statistical analysis was performed with the ANOVA test if samples were normally distributed or the Kruskal-Wallis test if the sample distribution was not normal. Simple linear regression was performed to analyse the effect of kynurenic acid in HDRS score and opioid dose. Multiple linear regression was used to analyse the correlation of kynurenic acid level with HDRS score and opioid dose simultaneously.

This research is a branch of a main research tree and has received ethical approval from the Health Research Ethics Committee of RSUD Dr. Soetomo Surabaya with ethics number 0155/KEPK/III/2021. 
RESULT AND DISCUSSION

Fifty-four patients were enrolled in this study. Sample characteristics were shown in Table 1

TABLE 1: Sample characteristics

\begin{tabular}{|l|cc|}
\hline \multicolumn{1}{|c|}{ Variable } & & Median (range) /n (\%) \\
\hline Sex & 11 & $(20,4 \%)$ \\
Male & 43 & $(79,6 \%)$ \\
Female & 54 & $(21-63)$ \\
\hline Age (years) & & $(24,1 \%)$ \\
\hline Diagnosis & 13 & $(29,6 \%)$ \\
Breast cancer & 16 & $(11,1 \%)$ \\
Cervical cancer & 6 & $(7,4 \%)$ \\
Nasopharyngeal cancer & 4 & $(27,8 \%)$ \\
Lung cancer & 15 & $(7,4 \%)$ \\
Others & & $(20,4 \%)$ \\
\hline Stadium & 4 & $(13,0 \%)$ \\
II & 11 & $(37,0 \%)$ \\
IIB & 7 & $(1,9 \%)$ \\
III & 20 & $(1,9 \%)$ \\
IIIB & 1 & $(13,0 \%)$ \\
IIIC & 1 & $(3,7 \%)$ \\
IIID & 7 & $(46,3 \%)$ \\
IV & 2 & $(53,7 \%)$ \\
IVB & & $(1-20)$ \\
\hline Pain duration & 25 & $(9,05-24,56)$ \\
3-6 months & 29 & \\
>6 months & 8 & \\
\hline HDRS score & 13,55 & \\
\hline Kynurenic acid level (nmol/L) & & \\
\hline
\end{tabular}

Note: Age, HDRS scores, and kynurenic acid levels are expressed in median (range) while others are expressed in $\mathrm{n}(\%)$.

In this study, majority of the samples were female (79.6\%). The median age of the sample in this study was 54 years, with a sample age range of 21 years to 63 years. The most common diagnosis from the sample of this study was cervical carcinoma (29.6\%), breast carcinoma (24.1\%), and nasopharyngeal carcinoma $(11.1 \%)$. Most of the samples were diagnosed with stage IIIB cancer (37.0\%). In this study, most of the samples had pain duration $>6$ months $(53.7 \%)$. The median HDRS score of the sample was 8 , with a range of 1 to 20 . Meanwhile, the median kynurenic acid level of the sample was $13.55 \mathrm{nmol} / \mathrm{L}$ with the lowest value of $9.05 \mathrm{nmol} / \mathrm{L}$ and the highest value of $24.56 \mathrm{nmol} / \mathrm{L}$. [Table 1]

This study demonstrated a significant relationship between kynurenic acid levels and the severity of depressive disorder $(\mathrm{p}<0,001)$, the severity of pain $(\mathrm{p}=0,001)$, and opioid requirement $(\mathrm{p}=0,007)$ in malignancy patients in palliative outpatient clinics. [Table 2]

We found significant relationship between kynurenic acid levels and the severity of depressive disorder in malignancy patients in the palliative care unit of Dr. Soetomo General Hospital Surabaya $(\mathrm{p}<0.001)$ [Table 1]. The group without depression had the highest median kynurenic acid level which was $16.08 \mathrm{nmol} / \mathrm{L}$, with a range of values from 11.24 $\mathrm{nmol} / \mathrm{L}$ to $24.56 \mathrm{nmol} / \mathrm{L}$. Meanwhile, patients with moderate and severe depressive disorder had lower median kynurenic acid levels, which were $11.18 \mathrm{nmol} / \mathrm{L}$ (9.05 $\mathrm{nmol} / \mathrm{L}-17.06 \mathrm{nmol} / \mathrm{L}$ ) and $12.69 \mathrm{nmol} / \mathrm{L}$, respectively.

TABLE 2: The relationship between kynurenic acid level and the severity of depressive disorder

\begin{tabular}{|c|c|c|}
\hline $\begin{array}{l}\text { Severity of depressive } \\
\text { disorder }\end{array}$ & $\begin{array}{l}\text { Kynurenic acid } \\
\text { level (nmol/L) }\end{array}$ & $P$ value \\
\hline No depression $(n=25)$ & $\begin{array}{c}16,08 \\
(11,24-24,56) \\
\end{array}$ & $<0,001^{*}$ \\
\hline Mild (n=14) & $\begin{array}{c}15,53 \\
(11,96-23,46)\end{array}$ & \\
\hline Moderate $(n=14)$ & $\begin{array}{c}11,18 \\
(9,05-17,06)\end{array}$ & \\
\hline Severe $(n=1)$ & $\begin{array}{c}12,69 \\
(12,69-12,69) \\
\end{array}$ & \\
\hline Severity of pain & $\begin{array}{l}\text { Kynurenic acid } \\
\text { level (nmol/L) }\end{array}$ & $P$ value \\
\hline Mild (n=21) & $\begin{array}{c}16,29 \\
(11,68-24,56)\end{array}$ & $0,001^{*}$ \\
\hline Moderate $(n=28)$ & $\begin{array}{c}12,32 \\
(9,05-18,38)\end{array}$ & \\
\hline Severe $(n=5)$ & $\begin{array}{c}16,26 \\
(10,58-23,46)\end{array}$ & \\
\hline Opioid requirement & $\begin{array}{l}\text { Kynurenic acid } \\
\text { level (nmol/L) }\end{array}$ & $P$ value \\
\hline Codein 4 x 5 mg $(n=1)$ & $\begin{array}{c}18,38 \\
(18,38-18,38) \\
\end{array}$ & $0,007^{*}$ \\
\hline Codein 4 × 10 mg $(n=8)$ & $\begin{array}{c}16,45 \\
(10,48-24,56)\end{array}$ & \\
\hline Codein 4 x 15 mg $(n=9)$ & $\begin{array}{c}15,61 \\
(13,44-17,44)\end{array}$ & \\
\hline Codein 4 × 20 mg $(n=1)$ & $\begin{array}{c}22,85 \\
(22,85-22,85)\end{array}$ & \\
\hline Codein $6 \times 20 \mathrm{mg}(\mathrm{n}=14)$ & $\begin{array}{c}12,06 \\
(10,58-17,73) \\
\end{array}$ & \\
\hline MOIR 4 x $5 \mathrm{mg}(\mathrm{n}=5)$ & $\begin{array}{c}16,10 \\
(11,24-23,46)\end{array}$ & \\
\hline MOIR 6 x 5 mg $(n=10)$ & $\begin{array}{c}11,88 \\
(9,05-18,98)\end{array}$ & \\
\hline MST 2 x $10 \mathrm{mg}(\mathrm{n}=6)$ & $\begin{array}{c}14,54 \\
(11,96-17,88)\end{array}$ & \\
\hline
\end{tabular}

*Kruskall Wallis test, significant if $\mathrm{p}$ value $<0,05$ 
Simple linear regression test was carried out to see further relationship between kynurenic acid levels and HDRS scores (Figure 1). The relationship between kynurenic acid levels and the HDRS score shows negative correlation with moderate strength $(\mathrm{r}=-0.508)$ with a $\mathrm{p}$ value of $<0.001$, which means that the as kynurenic acid level increase, the lower the HDRS score will be. The coefficient of determination or R Square obtained is 0.258 which can be interpreted that kynurenic acid level have a contribution effect of $25.8 \%$ on the HDRS score and the other $74.2 \%$ is influenced by other factors not examined. Mathematically, the linear regression line equation Y (HDRS score) = $20.604-0.805^{*} \mathrm{X}$ (kynurenic acid content). The regression coefficient for kynurenic acid content was -0.805 and stated that for every addition of $1.0 \mathrm{nmol} / \mathrm{L}$ kynurenic acid content, the HDRS score will decrease by 0.805 points.

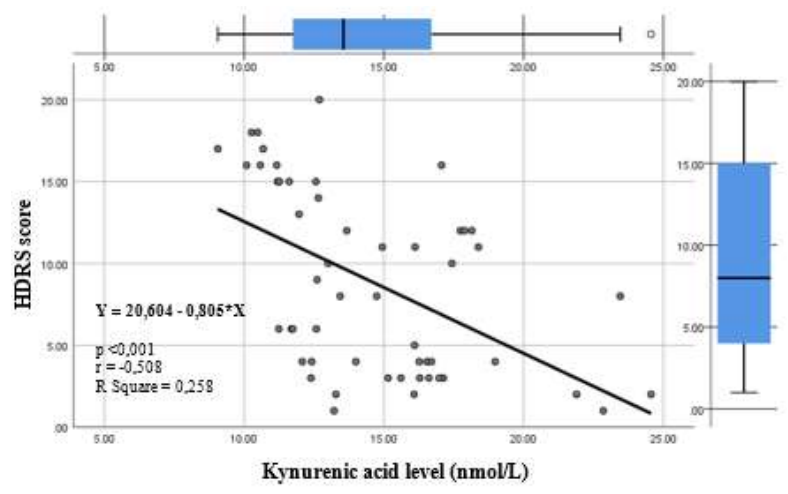

FIGURE 1: Confounding diagram of the correlationregression of kynurenic acid level with the HDRS score

The relationship between kynurenic acid levels and the HDRS score shows negative correlation with moderate strength of the correlation, which means that the higher the levels of kynurenic acid, the lower the HDRS score. The results of this study are in line with previous studies related to kynurenic acid levels with depressive disorders. Erabi et al. demonstrated a significant reduction in plasma kynurenic acid levels in patients with major depression compared to controls. (18) A recent meta-analysis of metabolites in the kynurenine pathway in patients with depressive disorders reported that KYNA levels were decreased in patients with depressive disorders. Four of 17 studies on KYNA showed lower levels of KYNA in patients with depressive disorders than controls.(19) Another recent study suggested KYNA as a potential biomarker in diagnosing depressive disorder patients.(15) In addition to decreased levels of KYNA in major depressive disorder, a recent study demonstrated that administration of KYNA induced antidepressant-like effects in an animal model of depressive disorder.(16) In this study, there was only one individual with major depression. These results may affect the results of the analysis in this study and are less representative of the actual situation in the population. However, the analysis results in patients with no depression to moderate depression can be considered to be representative of the condition in the population.

Metabolic factors in the kynurenine pathway have been widely recognized as an essential mechanism in major depressive disorder (MDD). QUIN are N-methyl Daspartate (NMDA) receptor agonists, which have neurotoxic effects, while KYNA is an NMDA receptor antagonist that exerts a neuroprotective effect. $(18,20)$ Although this study found that kynurenic acid levels had a contribution effect of $25.8 \%$ on the HDRS score, depression in patients could be influenced by other factors, such as biological, psychological, and socio-demographic factors. Obeid et al. examined the validation of HDRS in patients with depressive disorders. The study emphasized that socio-demographic factors such as socioeconomic level, divorce, and family history of mental disorders significantly increased the HDRS score, while education significantly decreased the HDRS score.(21) Biological factors at risk for depressive disorders in patients with malignancy include the type of cancer, stage of cancer, uncontrolled physical symptoms, inflammatory factors, and therapy-related factors.(22) Other factors related to major depression and may affect the increase of HDRS score are the frequency of chemotherapy, advanced stage of malignancy, length of illness, and several factors that are indirectly related to depression in cancer patients are the support of friends, family, health personnel, family income, occupation, education, and marital status.(23) The severity of fatigue, pain, stressors, and anxiety is the most significant factor in depressive disorders in cancer patients. $(24,25)$ Lee et al. stated that health problems, death of family members or friends, relatives with serious illnesses, and financial crises are the most common stressors faced by people with cancer.(24)

Most patients in this study experienced moderate to severe pain, with the highest prevalence being moderate pain as much as $51.9 \%$. The results of this study also showed that most of the patients were at stage III or above. This result may imply that the majority of patients presenting with advanced malignancy experience moderate to severe pain. The results of this study are consistent with previous studies, which stated that as many as $56 \%$ of adult cancer patients experienced moderate to severe pain.(26) The results of this study are slightly different from those of Van Den Beuken-Van Everdingen et al. who reported the prevalence of moderate to severe pain as much as 38\%, but the study stated that the prevalence of pain was relatively high in patients with advanced malignancy, metastases, and terminal stages, which was $66.4 \%$.(27) Cancer is not the only determinant that affects the pain patients perceive with malignancy, but also because of cancer treatment or other etiologies unrelated to cancer.(28)

In this study, we found significant relationship between kynurenic acid level and the severity of pain $(p=0.001)$ [Table 1]. The group with mild pain had the highest median kynurenic acid level, which was $16.29 \mathrm{nmol} / \mathrm{L}$, with a value range of $11.69 \mathrm{nmol} / \mathrm{L}$ to $24.56 \mathrm{nmol} / \mathrm{L}$. Meanwhile, patients with moderate pain had a lower median kynurenic acid level than mild pain, which was $12.32 \mathrm{nmol} / \mathrm{L}$ ( $9.05 \mathrm{nmol} / \mathrm{L}$ - $18.38 \mathrm{nmol} / \mathrm{L})$. However, patients with severe pain had a higher median kynurenic acid level than moderate pain, which was $16.26 \mathrm{nmol} / \mathrm{L}$ $(10.58 \mathrm{nmol} / \mathrm{L}-23.46 \mathrm{nmol} / \mathrm{L})$.

These results may illustrate that kynurenic acid levels have a protective effect on the development of pain in malignancy patients. Chronic pain experienced by patients with malignancy often coexists with depressive disorders. Previous studies stated that as many as $85 \%$ of patients with depression suffer from various pain conditions, so it can be believed that chronic pain and depressive disorders share the exact pathophysiological mechanisms, anatomical structures, neurotransmitters, and signaling pathways. $(29,30)$ Previous studies stated that kynurenic acid has anti-inflammatory, antioxidant, anti-excitotoxic, and immunomodulatory properties that play a role in the pathogenesis of mental disorders such as Alzheimer's and major depression. However, research on its role in pain is still limited to animal trials. (11)

Pain in malignancy involves a mixed mechanism of inflammatory, neuropathic, somatic, and visceral pain and cancer-specific pain. (31-33) Inflammation-induced kynurenine pathways and metabolites have been suggested 
to play a role in various psychoneurological symptoms in patients with malignancy. However, studies have inconsistent results regarding the exact relationship between kynurenine metabolites and these psychoneurological symptoms. These differences can be influenced by the type and stage of cancer, cancer therapy, anti-depressant drugs, age, and gender. The meta-analysis study by Li et al. mentions that there are still few studies that measure kynurenic acid (KYNA) and quinolinic acid (QA) on the imbalance of neuroprotective and neurodegenerative effects in the kynurenine pathway. (34) Most studies did not measure the downward pathway of kynurenic and quinolinic acids. Previous research by Huang et al. and Lyon et al., who investigated the kynurenine metabolite pathway with psychoneurological symptoms, stated that a decrease in Trp was associated with an increase in pain and was found in progressive malignancies. $(35,36)$ Trp levels were not studied in this study but decreased Trp levels are associated with activation of the kynurenine pathway, which may underlie the pathomechanism of pain in malignancy.

Pre-clinical model studies have shown an upregulation of IDO-1 mRNA in the contralateral hippocampus, resulting in complete Freund's adjuvant-induced arthritis of the hind limbs (complete Freud's adjuvant $=\mathrm{CFA}$ ) and marked behavioral depression in Wistar rats.(11) The molecular mechanism underlying these observations could be low serotonin (5-HT) levels and higher QA levels due to upregulation of the IDO-1 enzyme.(35) Under physiological conditions, tryptophan is mostly degraded to $\mathrm{N}$-formylkynurenine (NFK), but malignancy's chronic inflammatory and immune response conditions cause an increase in IDO-1 activity. This activity triggers the infiltration of macrophages, microglia, and dendritic cells, which are the largest source of quinolinic acid production and mediate the increase in quinolinic acid concentrations in the brain. $(37,38)$ This process causes the depletion of kynurenic acid levels because the metabolic process shifts towards the formation of quinolinic acid. In addition, quinolinic acid causes neurotoxicity in brain tissue, including astrocytes and glial cells, which are the main production sites of the neuroprotective metabolite kynurenic acid. Quinolinic acid acts as an NMDA receptor agonist and activates the receptor, causing the release of glutamate and inhibiting glutamate re-uptake by astrocytes causing neurotoxicity in glial cells and astrocytes. Damage to astrocytes causes reduced quinolinic acid levels, thereby reducing neuroprotective activity against quinolinic acid. (39)

Cosi et al. (2011) previously conducted a study on experimental animals that analyzed how kynurenic acid has an antinociceptive effect through the orphan G-protein receptor-35 (GPR35). The results of the study stated that kynurenic acid stimulation was able to reduce inflammatory pain. (40) Micromolar kynurenic acid levels can selectively antagonize NMDA receptors and reduce neuronal excitotoxic damage. Concentrations of nanomolar kynurenic acid can effectively reduce glutamate release and extracellular glutamate levels in various brain regions, thereby reducing excitatory transmission and protecting neuronal excitotoxic damage. The nanomolar levels of kynurenic acid were also able to inhibit the release of heat-shock-induced FGF $\alpha$ from non-neuronal cells and the release of neurotrophins in damaged or inflamed tissues, which are important events of nociceptor activation. KYNA, through the abundant GPR35 receptor in the dorsal root ganglia, can reduce the release of pro-inflammatory cytokines by cells. Inhibition of the release of inflammatory mediators in glial cells and macrophages may explain the analgesic effect of KYNA in experimental animal models of inflammation. $(41,42)$ Kynurenic acid affects the central nervous system, namely antagonist of glycine sites at the NMDA receptor, which is known to relieve pain in several animal studies.(43) Previous research by Csáti et al. conducted an animal trial to analyze the effect of kynurenic acid on activation of trigeminal pain induced by the administration of complete Freund's adjuvant (CFA), which causes local inflammation in the temporomandibular joint. The results showed an inhibition of the signaling system of the trigeminal ganglion after the administration of KYNA and its derivative kynurenic acid amide 2 (KYNAA2). (44)

In addition to the NMDA receptor, kynurenic acid is a neuroactive metabolite that interacts with various receptor targets such as nicotinic alpha-7 and AMPA/kainate receptors, but few studies have investigated the role of each receptor. Research by Tuboly et al.clarified the role of these receptors on the action of kynurenic acid at the spinal level by using synthetic molecules antagonists of the NMDA, AMPA/kainate, and nicotinic alpha-7 receptors to mimic the effects of KYNA. KYNA-influenced receptors (NMDA, AMPA) are expressed in the spinal cord. The results of this study showed that all of these molecules exerted an antinociceptive effect with motor disturbances. Kynurenic acid is also known to have an effect similar to local anesthetic drugs at the spinal cord level. The study results indicate that the inhibition of AMPA receptors by synthetic molecules KYNA has an anti-allodynic effect, suggesting that AMPA receptor activation plays a role in chronic pain processes. KYNA works by blocking the glutamate receptor on the NMDA receptor, which is involved in maintaining chronic pain. (45)

The kynurenic acid level in the severe pain group was higher than the moderate pain group in this study. The results in this study may be influenced by the small number of samples in the severe pain group, so it cannot describe the actual kynurenic acid levels, although they are statistically significant. In addition, the researchers did not analyze other metabolites such as quinolinic acid that may play a role in changes in kynurenic acid levels in the body so that the levels of kynurenic acid in the severe pain group appear to be higher. In contrast, the quinolinic acid levels in the severe pain group may be higher than in other pain groups. The measurement of quinolinic acid may describe the KYNA/QA ratio, which is vital to describe the balance of quinurenic acid and quinolinic acid that plays a role in the symptoms of neuropsychological disorders. The KYNA/QA ratio describes the relative amount of kynurenic acid to quinolinic acid. This ratio can be considered better than the absolute value of each metabolite because the KYNA and QA metabolite pathways exist simultaneously, but under several conditions, they compete for physiological effects and provide different effects. (46)

We also found a significant relationship between kynurenic acid level and the need for opioids in malignancy patients in the palliative care unit of Dr. Soetomo General Hospital Surabaya $(p=0.007)$ [Table 1]. In patients receiving codeine, the kynurenic acid levels were highest in the group requiring the smallest codeine dose, which was $4 \times 5 \mathrm{mg}$ and the lowest kynurenic acid level in the group requiring the highest codeine dose, which was 6 × $20 \mathrm{mg}$. Similarly, in the group of patients receiving MOIR, kynurenic acid levels were found to be lower in patients requiring a higher MOIR dose of 6 × $5 \mathrm{mg}$ than in patients requiring 4 × $5 \mathrm{mg}$ MOIR doses. Thus, lower kynurenic acid levels are associated with higher opioid dose requirements.

Simple linear regression also showed a significant relationship between kynurenic acid level and the need for opioid doses in malignancy patients in the palliative clinic of RSUD Dr. Soetomo Surabaya $(\mathrm{p}=0.004)$, with a correlation coefficient of -0.378 . Thus, lower kynurenic acid level was associated with higher opioid dose requirement (Figure 2). 


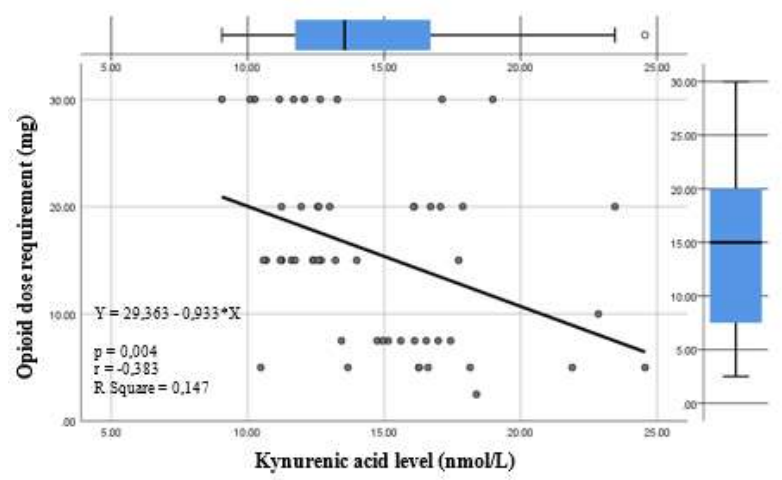

FIGURE 2: Confounding diagram of the correlationregression of kynurenic acid level with opioid dose requirement (MME)

This study showed a significant relationship between kynurenic acid levels and the need for opioids in malignancy patients in the outpatient palliative clinic. The kynurenic acid levels were highest in the group requiring the smallest opioid dose, and the lowest kynurenic acid levels were in the group requiring the largest opioid dose. This finding illustrates the inverse relationship between kynurenic acid levels and the need for opioids; particularly, the lower the kynurenic acid level, the higher the need for opioids. An inverse relationship between quinurenic acid levels and the degree of pain was also found in this study, which may be related to opioid dose regulation, so that the higher the kynurenic acid level, the lower the pain level and the lower the opioid dose. No study analyzes the relationship of kynurenic acid with the use of opioids in patients with malignancy. The most likely explanation to explain the results of this study is that the relationship between kynurenic acid and opioid tolerance may be related to opioid dose regulation in patients with malignancy. Problems encountered by doctors in managing pain in malignancy are the effects of chronic use of opioids that cause opioid tolerance and the emergence of a paradoxical pain sensation called opioid-induced hyperalgesia $(\mathrm{OIH})$. Higher doses of opioids are needed to maintain pain inhibition after repeated drug exposure. The potential of opioids as cancer pain therapy is limited by the duration of opioid use.(33) The mechanism of development of morphine tolerance itself is not fully understood, and the mechanism of action of kynurenic acid in reducing opioid tolerance has not been well studied because there is no evidence of a specific receptor involvement that mediates the efficacy of kynurenic acid, but data from receptor binding studies conducted by previous investigators allow to determine potential receptor mechanisms that may be involved.(47)

Several hypotheses implicate a role for increased glutamatergic signaling and decreased GABA-ergicsignaling. Increased expression of AMPA and NMDA receptor subunits and increased NMDA receptor binding were found in trials of rats with opioid tolerance. Blockade of spinal cord glutamatergic signaling by intrathecal injection of NMDA and AMPA antagonists can abolish opioid tolerance. Experimental data suggest that NMDA antagonists can potentiate the analgesic effect of opioids and block the development of tolerance after long-term opioid administration. $(47,48)$ Previous research on mice by Marek et al. on the tolerance of opioids and kynurenic acid, which is one of the excitatory amino acids (EAA), showed that administration of EEA, namely kynurenic acid and a specific NMDA receptor antagonist (MK-801), significantly reduced morphine tolerance in the tested mice with a hot plate test.(49)

Inhibition of alpha-7 nAChRs by KYNA may also play a role in modulating both central and peripheral pain transmission.
Stimulation of nAChR neurons excites or sensitizes peripheral sensory nerve fibers and also mediates cholinergic antinociception. Previous studies have shown that activation of alpha7 nAChR can exert antinociceptive effects in inflammatory pain models with peripheral mechanisms. (47) In addition, KYNA also interacts with AMPA and kainate receptors and GPCR receptors that interact with opioid receptors. KYNA can affect ionotropic glutamate receptors (such as NMDA, AMPA, and kainate receptors), which are ligand-gated non-selective cation channels and alter sodium ion concentration, thereby triggering changes in opioid receptor binding. (50) These mechanisms may underlie the association of quinurenic acid in decreasing morphine tolerance.

\section{CONCLUSION}

Based on the results of the study, we conclude that kynurenic acid level had a negative correlation with severity of depressive disorder, severity of pain, and opioid dose requirement.

\section{REFERENCES}

[1] WHO. WHO report on cancer: setting priorities, investing wisely and providing care for all. World Health Organization. 2020.160 p.

[2] International Agency for Research on Cancer (IARC) / WHO. GLOBOCAN 2020: Estimated cancer incidence, mortality, and prevalence worldwide in 2020 [Internet]. 2020. Available from: https://gco.iarc.fr/today/data/factsheets/population s/900-world-fact-sheets.pdf

[3] Kementerian Kesehatan RI. Pusat Data dan Informasi: Situasi Penyakit Kanker. 2015.

[4] Kementerian Kesehatan RI. Pedoman Teknis Pelayanan Paliatif Kanker [Internet]. 2013. 98 p. Available from: https://www.academia.edu/34128394/PEDOMAN_T EKNIS_PELAYANAN_PALIATIF_KANKER

[5] WHO. Knowledge into Action Palliative Care. Cancer Control. 2007;1-42.

[6] Komite Penanggulangan Kanker Nasional. Panduan Penatalaksanaan Kanker Paru. Kementerian Kesehatan Republik Indonesia

[7] Klepstad P, Kaasa S, Cherny N, Hanks G, de Conno F. Pain and pain treatments in European palliative care units. A cross sectional survey from the European Association for Palliative Care Research Network. Palliat Med. 2015; 19:477-84.

[8] Effendy C, Vissers K, Osse BH, Tejawijaya S, VernooijDagsen M, Engels Y. Comparison of problems and unmet needs of patients with advanced cancer in a European country and an Asian country. Pain Pr. 2014; 5:433-40.

[9] Koningan A. Depresi pada penderita kanker-pusat pengembangan paliatif dan bebas nyeri RSU Dr. Soetomo Surabaya. Pus Pengemb Paliat dan bebas nyeri. 2008

[10] Teodora BA, Ianovici N, Bancilla S. Modifying factors of chronic pain perception in oncology patient. Ther Pharmacol Clin Technol. 2012;16(2):226-31.

[11] Jovanovic F, Candido KD, Knezevic NN. The role of the kynurenine signaling pathway in different chronic pain conditions and potential use of therapeutic agents. Int J Mol Sci. 2020;21(17):1-17. 
[12] Amirdelfan K, Pope JE, Gunn J, Hill MM, Cotten BM, Beresh JE, et al. Clinical Validation of a MultiBiomarker Assay for the Evaluation of Chronic Pain Patients in a Cross-Sectional, Observational Study. Pain Ther [Internet]. 2020;9(2):511-29. Available from: https://doi.org/10.1007/s40122-020-00175-3

[13] Savitz J. The kynurenine pathway: a finger in every pie. Mol Psychiatry. 2020;25(1):131-47.

[14] Ogyu K, Kubo K, Noda Y, Iwata Y, Tsugawa S, Omura Y et al. Kynurenine pathway in depression: A systematic review and meta-analysis. Neurosci Biobehav Rev. 2018;90(2010):16-25.

[15] Liu H, Ding L, Zhang H, Mellor D, Wu H, Zhao D. The Metabolic Factor Kynurenic Acid of Kynurenine Pathway Predicts Major Depressive Disorder. Front Psychiatry 9552. 2018;9(552).

[16] Tanaka M, Bohár Z, Martos D, Telegdy G, Vécsei L. Antidepressant-like efects of kynurenic acid in a modifed forced swim test. Pharmacol Rep. 2020;72:449-455.

[17] Walczak K, Wnorowski A, Turski WA, Plech T. Kynurenic acid and cancer: facts and controversies. Cell Mol Life Sci. 2020;77(8):1531-50.

[18] Erabi H, Okada G, Shibasaki C, Setoyama D, Kang D, Takamura $\mathrm{M}$, et al. Kynurenic acid is a potential overlapped biomarker between diagnosis and treatment response for depression from metabolome analysis. Sci Rep [Internet]. 2020;10(1):1-8. Available from: https://doi.org/10.1038/s41598-020-73918-z

[19] Ogyu K, Kubo K, Noda Y, Iwata Y, Tsugawa S, Omura Y, et al. Kynurenine Pathway in Depression: A Systematic Review and Meta-analysis. Neurosci Biobehav Rev. 2018; Jul (90):16-25.

[20] Myint A, Ku Y, Verkerk R, Scharpé S, Steinbusch H, Leonard B. Kynurenine pathway in major depression: Evidence of impaired neuroprotection. J Affect Disord. 2007; 98:143-51.

[21] Obeid S, Abi Elias Hallit C, Haddad C, Hany Z, Hallit S. Validation of the Hamilton Depression Rating Scale (HDRS) and sociodemographic factors associated with Lebanese depressed patients. Encephale. 2018;44(5):397-402.

[22] Caruso R, Nanni MG, Riba M, Sabato S, Mitchell AJ, Croce $\mathrm{E}$, et al. Depressive spectrum disorders in cancer: prevalence, risk factors and screening for depression: a critical review. Acta Oncol (Madr). 2017;56(2):146-55.

[23] Shinta D, Tamtomo DG, Soemanto R. Factors Affecting Occurrence of Depression in Patients with Cervical Cancer at Dr. Moewardi Hospital Surakarta, Central Java: A Path Analysis Model. J Epidemiol Public Heal. 2019;4(4):338-50.

[24] Lee Y, Lin PY, Lin MC, Wang CC, Lu HI, Chen YC, et al. Morbidity and associated factors of depressive disorder in patients with lung cancer. Cancer Manag Res. 2019; 11:7587-96.

[25] Karawekpanyawong N, Kaewkitikul K, Maneeton B, Maneeton N, Siriaree S. The prevalence of depressive disorder and its association in Thai cervical cancer patients. PLoS One. 2021;16(6 June):1-16.

[26] Breivik H, Cherny N, Collett B, de Conno F, Filbet M, Foubert AJ, et al. Cancer-related pain: A pan-European survey of prevalence, treatment, and patient attitudes.
Ann Oncol. 2009;20(8):1420-33.

[27] Van Den Beuken-Van Everdingen MHJ, Hochstenbach LMJ, Joosten EAJ, Tjan-Heijnen VCG, Janssen DJA. Update on Prevalence of Pain in Patients with Cancer: Systematic Review and Meta-Analysis. J Pain Symptom Manage. 2016;51(6):1070-1090.e9.

[28] Caraceni A, Shkodra M. Cancer pain assessment and classification. Cancers (Basel). 2019;11(4).

[29] Bair MJ, Robinson RL, Katon W, Kroenke K. Depression and Pain Comorbidity. Arch Intern Med. 2003; 163:2433-45.

[30] Meerwijk EL, Ford JM, Weiss SJ. Brain regions associated with psychological pain: Implications for a neural network and its relationship to physical pain. Brain Imaging Behav. 2013;7(1):1-14.

[31] Levy MH, Chwistek M, Mehta RS. Management of chronic pain in cancer survivors. Cancer J. 2008;14(6):401-9.

[32] Raphael J, Ahmedzai S, Hester J, Urch C, Barrie J, Williams J, et al. Cancer pain: part 1: Pathophysiology; oncological, pharmacological, and psychological treatments: a perspective from the British Pain Society endorsed by the UK Association of Palliative Medicine and the Royal College of General Practitioners. Pain Med. 2010;11(5):742-64.

[33] Falk S, Bannister K, Dickenson AH. Cancer pain physiology. Br J Pain. 2014;8(4):154-62.

[34] Li H, Liu T, Heinsberg LW, Lockwood MB, Wainwright DA, Jang MK, et al. Systematic Review of the Kynurenine Pathway and Psychoneurological Symptoms Among Adult Cancer Survivors. Biol Res Nurs. 2020;22(4):472-84.

[35] Huang A, Fuchs D, Widner B, Glover C, Henderson DC, Allen-Mersh TG. Serum tryptophan decrease correlates with immune activation and impaired quality of life in colorectal cancer. Br J Cancer. 2002;86(11):1691-6.

[36] Lyon DE, Starkweather A, Yao Y, Garrett T, Kelly DL, Menzies V, et al. Pilot Study of Metabolomics and Psychoneurological Symptoms in Women with Early Stage Breast Cancer. Biol Res Nurs. 2018;20(2):227-36.

[37] Chen Y, Guillemin GJ. Kynurenine pathway metabolites in humans: Disease and healthy states. Int J Tryptophan Res. 2009;2(1):1-19.

[38] Davis I, Liu A. What is the tryptophan kynurenine pathway and why is it important to neurotherapy? Expert Rev Neurother. 2015;15(7):719-721.

[39] Baranyi A, Meinitzer A, Breitenecker RJ, AmouzadehGhadikolai O, Stauber R, Rothenhäusler HB. Quinolinic acid responses during interferon- $\alpha$-induced depressive symptomatology in patients with chronic hepatitis $\mathrm{C}$ infection-A novel aspect for depression and inflammatory hypothesis. PLoS One. 2015;10(9):1-13.

[40] Cosi C, Mannaioni G, Cozzi A, Carl V, Sili M, Cavone L, et al. G-protein coupled receptor 35 (GPR35) activation and inflammatory pain: Studies on the antinociceptive effects of kynurenic acid and zaprinast. Neuropharmacology. 2011;60(7-8):1227-31.

[41] Moroni F, Cozzi A, Sili M, Mannaioni G. Kynurenic acid: A metabolite with multiple actions and multiple targets in brain and periphery. J Neural Transm. 2012;119(2):133-9. 
[42] Rojewska E, Ciapała K, Mika J. Kynurenic acid and zaprinast diminished CXCL17-evoked pain-related behaviour and enhanced morphine analgesia in a mouse neuropathic pain model. Pharmacol Reports. 2019;71(1):139-48.

[43] Kekesi G, Joo G, Csullog E, Dobos I, Klimscha W, Toth K, et al. The antinociceptive effect of intrathecal kynurenic acid and its interaction with endomorphin1 in rats. Eur J Pharmacol. 2002;445(1-2):93-6.

[44] Csáti A, Edvinsson L, Vécsei L, Toldi J, Fülöp F, Tajti J, et al. Kynurenic acid modulates experimentally induced inflammation in the trigeminal ganglion. J Headache Pain. 2015;16(1):1-14.

[45] Tuboly G, Tar L, Bohar Z, Safrany-Fark A, Petrovszki Z, Kekesi G, et al. The inimitable kynurenic acid: The roles of different ionotropic receptors in the action of kynurenic acid at a spinal level. Brain Res Bull. 2015;112(September 2015):52-60.
[46] Savitz J, Dantzer R, Meier TB, Wurfel BE, Victor TA, McIntosh SA, et al. Activation of the kynurenine pathway is associated with striatal volume in major depressive disorder. Psychoneuroendocrinology. 2015; 62:54-8.

[47] László Mécs M. Peripheral antinociceptive effects of endogenous ligands (endomorphin-1, 2-arachidonoyl glycerol and kynurenic acid) in a joint pain model Faculty of Medicine Department of Physiology. 2010.

[48] Eidson LN, Murphy AZ. Inflammatory mediators of opioid tolerance: Implications for dependency and addiction. Peptides. 2019; 115:51-8.

[49] Marek P, Ben-Eliyahu S, Gold M, Liebeskind JC. Excitatory amino acid antagonists (kynurenic acid and MK-801) attenuate the development of morphine tolerance in the rat. Brain Res. 1991;547(1):81-8.

[50] Samavati R. Kynurenic acid and its amide analogue might be possible drug candidates for controlling the activity of opioid system. 2017. 